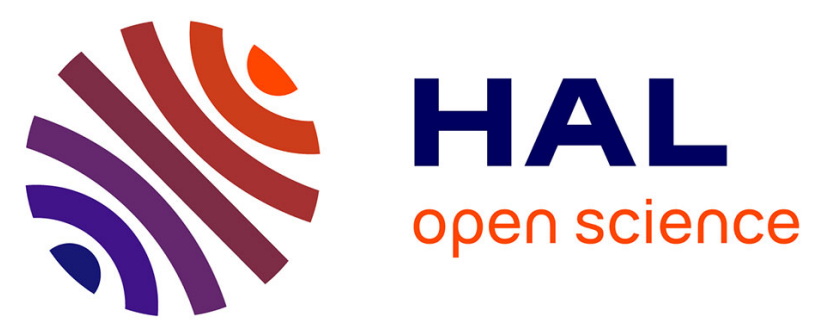

\title{
Complexity Management in the Semiconductor Supply Chain and Manufacturing Using PROS Analysis
}

\author{
Can Sun, Thomas Rose, Hans Ehm, Stefan Heilmayer
}

\section{To cite this version:}

Can Sun, Thomas Rose, Hans Ehm, Stefan Heilmayer. Complexity Management in the Semiconductor Supply Chain and Manufacturing Using PROS Analysis. 16th International Conference on Informatics and Semiotics in Organisations (ICISO), Mar 2015, Toulouse, France. pp.166-175, 10.1007/978-3-31916274-4_17. hal-01324975

\section{HAL Id: hal-01324975 \\ https://hal.inria.fr/hal-01324975}

Submitted on 1 Jun 2016

HAL is a multi-disciplinary open access archive for the deposit and dissemination of scientific research documents, whether they are published or not. The documents may come from teaching and research institutions in France or abroad, or from public or private research centers.
L'archive ouverte pluridisciplinaire HAL, est destinée au dépôt et à la diffusion de documents scientifiques de niveau recherche, publiés ou non, émanant des établissements d'enseignement et de recherche français ou étrangers, des laboratoires publics ou privés. 


\title{
Complexity Management in the Semiconductor Supply Chain and Manufacturing Using PROS Analysis
}

\author{
Can Sun ${ }^{1,2}$, Thomas Rose ${ }^{1,3}$, Hans Ehm², Stefan Heilmayer ${ }^{2}$ \\ ${ }^{1}$ RWTH Aachen University, Templergraben 55, 52062 Aachen, Germany \\ ${ }^{2}$ Infineon Technologies AG, Am Campeon 1-12, 85579 Neubiberg, Germany \\ ${ }^{3}$ Fraunhofer FIT, Schloss Birlinghoven, 53754 Sankt Augustin, Germany \\ \{Can.Sun, Hans.Ehm, Stefan.Heilmayer\}@infineon.com \\ Thomas.Rosedfit.fraunhofer. de
}

\begin{abstract}
Supply chain complexity is a rising problem, especially in the semiconductor industry. Many innovative activities occur in the daily supply chain and manufacturing, and these changes inevitably bring in the complexities to the organization. But not all of them are valuable to the business goals. Decision makers want to keep value-added complexity and reduce non-value-added complexity. To manage the complexity, we propose a framework with four steps from changes identification towards the final decision making. The core solution of this framework is PROS (process, role, object, state) idea, which provides an understandable and structural way to describe the complexity. A simplified small real example from semiconductor supply chain is used to demonstrate this approach. The results indicate that the PROS idea is able to analyze complexity from different aspects and extract most key information; however, how to measure the structural complexity of a large complex system without complete information is still under investigation.
\end{abstract}

Keywords: supply chain complexity - change management - process model · complexity assessment $\cdot$ semiconductor industry

\section{Introduction}

The semiconductor industry is considered to be one of the most complex industries. From the raw material of silicon to the advanced semiconductor chips, there are more than 500 processing steps involved in the manufacturing. It also faces a highly volatile and turbulent market due to economic cycles, which bring the challenge to manage dynamic production environments with the pace of change in the industry [1], [2], [3].

adfa, p. 1, 2011.

C Springer-Verlag Berlin Heidelberg 2011 
The semiconductor supply chain is characterized by long throughput times, high levels of stochasticity, non-linearity in the manufacturing process [4], and short product life cycles. These all lead to complexity to be managed in the supply chain. It is reflected as: network complexity (e.g. multiple production sites and global distribution centers), process complexity (manufacturing and business processes), product complexity (e.g. about 10,000 Stock keeping units and 500,000 order line item buckets), organizational complexity (e.g. many geographic regions with various tax and customs regulations), and information complexity (data structure and information flow) [5]. And all of them are interlinked.

Managing complexity in the supply chain adds value to business. According to A.T. Kearney's report, companies can increase their Earnings before interest and tax (EBIT) by 3 to 5 percent on average through systematic complexity management [6]. Many changes via innovations are ongoing in operational, tactical and strategic supply chain activities and thus complexities are added but not all of them are valuable to the business goals. Therefore, we need to distinguish: the "good" complexity which adds value to the supply chain whereas the "bad" one does not. Value-adding ("good") complexity offers ways to meet customer demands and create a real competitive advantage; while value-destroying ("bad") complexity dissatisfy customers and sends the company into chaos and confusion [6], [7]. These two different categories of complexity require companies to employ distinctive strategies. The value-adding complexity should be controlled efficiently to create value; for the value-destroying complexity, the part that does not add value needs to be eliminated, reduced and minimized [8], [9], and avoided in the early phase of generation.

In reality these two types of complexity often occur together and thus a strategic balance is demanding, e.g., lead firms increase complexity by placing new demands on the value chain and in parallel adopt strategies to reduce the complexity of these transactions [10]. This brings the challenges to detect the complexity-added part and then to evaluate them in order to get rid of the non-valuable parts and support decision making.

\subsection{Research Question}

My research aims to manage the complexities from the computer science view. By tracking the changes on the system level, the complexity drivers can be identified and described in a systematic way. After all the key information related to complexity being captured and structured, we can assess the complexity through selected instruments and categorize it as a value-added complexity or not. In the end, the results should be validated and thus can support decision making by applying corresponding strategies (e.g. reduce complexity, avoid complexity, etc.).

\subsection{Status of problem domain and related solutions}

Much relevant research has been done on complexity management. Literature shows that most analysis is on the theoretical level based on an abstract model instead of 
operational excellence on the practical level [11]. However, the mapping process from "a real complex problem" to "a defined model for complexity" is not much explored. Research on change management is mostly analyzed from the organizational view [12], small amount is viewed from the system engineering field, which is more related to the business process re-engineering and process management [13] and provides certain process meta-models or patterns for change management [14].We are more interested in the latter direction, however, the connection between model of system change and the complexity management is not obvious.

Complexity in a supply chain is often viewed from three aspects: product, process and organization [15], [16], [17]. Research on the complexity analysis usually focuses on certain aspects, e.g. product variety, while it is not common to consider the complexity from a holistic view. Considering the inter-dependencies of different aspects of complexity, we prefer to use a comprehensive approach to capture all the important features of a complex system.

Regarding the methods and instruments of complexity assessment, much research is on the strategic level and only provides qualitative evaluation; some quantitative methods are available but still lack practicability and tools [11], [15], [18], [19].To support decision making, we are also interested in the implementation details, such as, formal indicators and structural measurement.

From above analysis, it is seen that there is a gap between the existing approaches to handle complex problems and our objective. Therefore, we bring in a framework including 4 steps to manage complexity: 1) Identify complexity caused by changes 2 ) Represent complexity 3) Assess complexity via developed instruments 4) Evaluate and support decision making. In this paper we address the first three steps on a real problem from semiconductor industry, which are also expected to be beneficial in the last stage of decision making. And in the second step a proposed conceptual model called PROS to describe complexity is highlighted.

\section{Proposed approach}

\subsection{Identification of changes and complexity}

Change is one of the main reasons to cause the complexity, so our research starts from the change analysis. The goal of this step is to capture the complexity caused by changes on the detailed level. Two parts related to changes should be considered: the change itself and its impact to the system. The change itself, also referred to as the initial change or one-time-change, means the "effort to implement a change", which normally only execute once. For the impact of change, it is "the potential consequence of a change on a system or what needs to be modified of a system in order to accomplish a change" [20]. This often requires executing affected processes regularly in order to maintain the change of system. Both change related parts usually lead to increased complexity. The output of this step is the added processes during the initial change phase; and the affected processes during the maintenance phase. 


\subsection{Information Extraction and Representation - PROS idea}

The purpose of this step is to represent the complexity in a structural way without losing any important information. System models are employed to formalize the complexities receiving from the $1^{\text {st }}$ phase using modeling language such as SysML.

The premise to accurately describe supply chain complexity is to define the boundary of the complex system and its environment. We adopt a system delimitation technique from a generic Systems Engineering (SE) methodology to define the environment and intervention system [21], [22]. Some similar approaches, e.g., a knowledge representation language called Telos [23] can also be used to distinguish the environment in a later stage.

Once the investigation area is reduced, we can identify the elements and their relationships using the system consideration of SE. Then we develop a conceptual model called PROS (Process, Role, Object, State), which defines the basic elements and relationships in a complex system.

The idea of PROS originated from Object Process Methodology (OPM) [24], [25]. OPM defines three basic entities: objects with states and processes. Among them objects and processes are higher-level building blocks, while states are always associated with objects and cannot be state-alone. It can be used to model the complex dynamic systems and embedded into other models for specified application [26].

Also we notice that supply chain is similar to economic, ecological, and social systems, which are characterized by interactive "agents" (roles) [27], [28].Therefore, we assume role is as important as the object and process, while OPM only handles human as an instance of object. Comparing with OPM, PROS also considers the human behaviors and their initiatives.

PROS model is characterized by entities, relationships and constraints.

Entities. A Process is a pattern of transformation that an object undergoes; A Role is a person to execute a process. This definition can be extended to: A role could be a person, a department, a customer, a supplier or any other group of persons or a software tool to execute a process. An Object is a thing that has the potential of stable, unconditional physical or mental existence. A State is a situation or position at which the object can exist for a period of time.

Relationships. We customize the OPM relationship set [24] for our purpose and define 6 relevant pairs of relations: Process-Process, Process-Role, Process-State, Process-Object, Object-Object, Object-State. For each pair, there are one or more subrelationships. E.g., there are several different types of Process-State relationships. The attributes of these relationships are also defined: name, direction, symbols, dynamics, etc.

Constraints. Two constraints are highlighted: Cardinality and Relationship rule. Cardinality defines 3 types of data structure: one-to-one relationship, one-to-many relationship and many-to-many relationship. Relationship rules imply that all the relationship definitions should follow the rules of the above 6 pairs strictly. The cardinality constraints and relationship rule can be used together.

PROS Diagram and Prototype. In working with complex problems we found out that representation is an important goal for PROS. Thus we design a PROS diagram to visualize the entities and their relationships, which can be viewed as the integration of the use case and object diagram of UML notations. We also developed a prototype as 
shown in Fig.1. The layout divides the canvas into 5 areas, and each contains one independent diagram. In the area marked with 1, the navigation of the whole object diagram is shown. Area 2 shows the navigation of the complete process diagram. Area 3 shows the dynamic object and state diagram for a running process. It reflects the details and changes of the objects during the processing. Area 4 shows the roles involved in the process. Area 5 shows the running step for the process. Area 1 and 2 do not change during the whole process analysis, only the analyzed area of processes and objects is highlighted. Other areas change with the process step in analysis.

PROS analysis normally starts with the process aspect, similar to other system modeling languages like BPMN and UML. Besides this process-oriented analysis, the human-oriented analysis can also be applied. Agent-based modeling and simulation is a widely used technique to formalize the human (agents in broad definition) behavior and their interactions [29]. Another technique is goal-oriented modeling, e.g., $i$-Star approach can analyze the agents from the view of their personal goals and what activities could be done in order to achieve these goals [30].

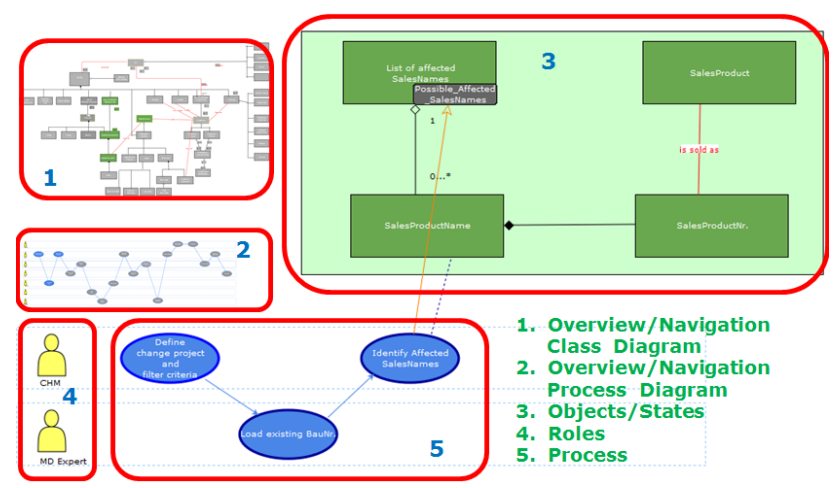

Fig. 1. Visualization Prototype for PROS

The results of the PROS analysis contain most key information from a complex system and which can be used as an input for the assessment step.

\subsection{Structural complexity measurement using PROS}

Structural complexity is about the complexity resulting from physical interconnection of components. It belongs to the physical domain and can be directly calculated from the elements and the relationships among them [15], [31]. Since this information can be received from the step 2, we can at least calculate the complexity oriented from elements (states of a system) and the complexity oriented from relationships (number of all connections). A further step measure is to calculate the entropy of statistical complexity based on the Shannon information theory [18].

Besides the basic quantity (size) information, we assume that the structural complexity is also decided by the attributes of each individual element, such as category, importance or diversity, and whether it is interrelated to the rest of system. We also need 
to highlight the impact of roles (often humans), as their behaviors can lead to uncertainty and thus complexity of the system. To be able to distinguish the complexity impact of different roles, we added a weight value for each role by considering the number of involved processes [32].

\section{Case Study}

\subsection{Shared reticle vs. mono reticle}

We select a case from semiconductor manufacturing to explain how complexity is generated. A set of reticles (up to 35) is needed to produce a wafer. In this paper we call the reticle set "reticle" for simplicity. Comparing with the as-is solution with mono reticle, an alternative solution using shared reticle could produce more products on one wafer, and thus reduce the quantity of reticles required. The reduction of reticle costs decreases manufacturing costs substantially.

There is certain degree of truth that, shared reticle technology is cost beneficial, but the flip side of the coin is that the change process from mono reticle to share reticle is not that simple. For example, certain processes need to be updated, people need to be motivated to accept the changes, etc., which leads to increased complexities.

Before making decision to adopt the shared reticle solution or not, it is necessary to assess its increased supply chain complexity and evaluate whether the reduced reticle cost offsets the increased complexity.

The cost saving from the economic view is given on monetary values; however, the change process and its increasing complexity are not systematically assessed. Current Business Process Management (BPM) solution cannot reflect all aspects of the complex problem, while other supply chain process models are not detailed on the operational level. This gap hinders the making of high-quality decisions.

\subsection{Results achieved so far}

By following the framework provided in section 2, we have achieved some intermediate results, which are mainly centered on the changes and complexities identification and measurement.

Changes and complexity identification and presentation. The change management can be analyzed from the aspects of process, organization (roles) via PROS.

The process analysis follows the supply chain operations reference-model (SCOR) model, the most widely accepted framework for standardization in supply chain management, developed by the Supply Chain Council ${ }^{1}$. It defines the first three levels of supply chain processes. The top level has 5 processes: Plan, Source, Make, Deliver and Return. Each level-1 process has 10-20 level-2 processes and spans multiple level-3 and 4 processes. Processes below level 3 are defined by the companies themselves. Following the SCOR model, the major processes of shared reticle up to level 4 can be identified.

\footnotetext{
${ }^{1}$ http://www.apics.org/sites/apics-supply-chain-council
} 
Considering around all 500 steps of Produce and Test Process (sub-process of Make) related to wafer manufacturing with mono and shared reticle, it can be roughly said that 480 steps are not changed. Complexity is mainly added in the Test process (for simplicity step 480 to 490 ) and the Optical Control process (for simplicity step 490 to 500). For the Plan Process, the overall planning including short-term plan and midterm plan need to be changed; and Front End Plan needs to be rescheduled.

The main affected processes and their added complexities are listed in Table 1. It is important to highlight which types of change the complexity belongs to, as this would be part of assessment on the next stage.

Table 1. Shared reticle: added complexity (CT means Change Types, O is one-time-change and $\mathrm{R}$ is regular maintenance)

\begin{tabular}{|c|c|c|c|}
\hline $\begin{array}{l}\text { SCOR } \\
\text { Model } \\
\text { Layer }\end{array}$ & Process Changed & Added complexity & CT \\
\hline 1.1 .2 & Make-Front End-Test & $\begin{array}{l}\text { Equipment reprogramming in order to } \\
\text { manage the changes }\end{array}$ & $\mathrm{O}$ \\
\hline 1.1 .2 & Make-Front End-Test & $\begin{array}{l}\text { For shared reticle, in testing at least } \\
\text { every second product is different and } \\
\text { thus the testing process needs to be } \\
\text { switched too. }\end{array}$ & $\mathrm{R}$ \\
\hline 1.1 .3 & $\begin{array}{l}\text { Make-Front End -Optical } \\
\text { Control }\end{array}$ & Equipment update & $\mathrm{O}$ \\
\hline 1.1 .3 & $\begin{array}{l}\text { Make-Front End -Optical } \\
\text { Control }\end{array}$ & Training the operators & $\mathrm{O}$ \\
\hline 1.1 .3 & $\begin{array}{l}\text { Make-Front End -Optical } \\
\text { Control }\end{array}$ & $\begin{array}{l}\text { More operators are allocated to work } \\
\text { with optical inspections systems }\end{array}$ & $\mathrm{O}$ \\
\hline 1.1 .3 & $\begin{array}{l}\text { Make-Front End -Optical } \\
\text { Control }\end{array}$ & Monitor the optical inspection systems & $\mathrm{R}$ \\
\hline 2.1.1 & Plan- Production Program & Overall planning processes are changed & $\mathrm{O}$ \\
\hline 2.1 .1 & Plan- Production Program & $\begin{array}{l}\text { Execute the changed planning process- } \\
\text { es }\end{array}$ & $\mathrm{R}$ \\
\hline
\end{tabular}

We also notice that the stakeholders' attitudes towards these affected processes may influence the new solution and thus lead to complexity. Research shows people may not like change or may not adopt changes [33], [34]. Therefore, we need to consider the human goals in order to measure complexity accurately in the next step.

Based on the interviews and process analysis, we identify the key stakeholders involved in the change project and assess their interests. Here a goal-oriented modeling approach is employed, e.g., $i$-Star can be used to analyze personal goals and behaviors of alternative solutions [30]. For each stakeholder, first we analyze their goals and corresponding actions, and then we can check how these actions benefit or hurt their goals. By doing that the relationships among stakeholders are detected too. One part of our result shows that, test engineer does not like to accept the change as it hurts his goal while the development engineer is motivated for this change.

The main object involved in this change is wafer and its states are related to the different stages of manufacturing process steps.

PROS approach can be used as a guide to obtain the key elements of processes, roles and objects, as well as different relationships. We could gain this information: 
- Description about the stakeholders and their goals

- Description about the changed process

- Description about the objects and their states involved in the processes

- Partial information about the dependencies network

Complexity assessment. We can get statistic information from above analysis, e.g., the change includes 4 processes and 10 sub-processes, 7 roles and 2 objects with 10 states. Using the measurement methodology proposed in section 2.3, we can calculate its element complexity. However, for the relationships among these elements, it is not easy to detect all dependencies within a large complex system.

Besides that, we should measure the different types of process changes separately. Table 1 shows two types of changes: the one-time-change needs only to be calculated once, while the regular maintenance needs to be calculated periodically.

To evaluate whether the benefits of a new solution outweigh the added complexity, we could calculate the deviated complexity from two solutions (the changes part) and compare it with the saved costs. For example, if the cost of added complexity is smaller than the saved reticle benefits, we can identify "switch to shared reticle" as a value-adding complexity, otherwise, it is the value-destroying complexity.

\subsection{Discussion}

It is seen from above analysis, PROS approach helps to analyze from different aspects: the processes and their required changes, people and their conflicts. However, for a large complex system, it is not feasible to use an exhaustive method to detect all relationships between elements. How to estimate the relationship intelligently (sufficiently accurate within a given time) is still a challenge for us.

The lessons learned focus on two areas: 1) each aspect of a complex problem can be detailed and deeply analyzed by following a certain model or method - e.g., process analysis with SCOR, role analysis with goal-oriented mode. For large systems the accuracy within a given time is a challenge. 2) The qualitative analysis is not sufficient for decision making, to make better decision we need to quantify complexity oriented from all aspects of a system. The PROS approach is promising but a formula ending up with a complexity number is still missing.

\section{Conclusion and Future Work}

This paper introduces a framework to manage supply chain complexity from computer science view, which sets up a connection between change management and complexity management. We conclude that complexity should be managed from a systematic view instead of the single aspect.

The core part of this framework is the PROS conceptual model, which represents and visualizes the complex system by capturing its important elements and relationships. It can supplement the quantitative complexity measurement by separating it into the elements and relationships part. Calculating the numerous relationships in a large system requires more sophisticated methodologies. 
An industrial case from the semiconductor industry with two alternative solutions is analyzed from different aspects and the measurement of added complexity is discussed in order to select the optimal solution. The framework is not limited to the semiconductor industry or supply chain field and could be extended to a broad area: project management, organization changes, government policy analysis, etc.

In future research we optimize the PROS approach to larger systems and improve the quantitative measurement of complexity. Two aspects will be addressed: 1) Understand and track the dynamic interaction between elements. 2) Investigate the weight value of human behaviors and their impact, and other components leading to uncertainties and thus complexity of the system.

\section{References}

1. Uzsoy, R., Lee, C. Y., \& Martin-Vega, L. A.: A Review Of Production Planning And Scheduling Models In The Semiconductor Industry Part I: System Characteristics, Performance Evaluation And Production Planning. IIE Transactions 24.4 (1992) 47-60

2. Harald Bauer, Iana Kouris, Gernot Schlögl, Thomas Sigrist, Jan Veira, Dominik Wee: Mastering Variability In Complex Environments. Mckinsey Semiconductors, Autumn 2011

3. Emami-Naeini, A., \& De Roover, D.: Control in Semiconductor Wafer Manufacturing. Proc. Symposium To Honor Bill Wolovich, 47th IEEE Conference On Decision And Control, Cancun, Mexico. 2008

4. Wang, W., \& Rivera, D. E.: Model Predictive Control For Tactical Decision-Making In

5. Semiconductor Manufacturing Supply Chain Management. Control Systems Technology, IEEE Transactions On 16.5 (2008) 841-855

6. Christopher, Martin: The Agile Supply Chain: Competing In Volatile Markets. Industrial Marketing Management 29.1 (2000) 37-44

7. Scheiter, S., Scheel, O., Klink, G.: How Much Does Complexity Really Cost? A.T. Kearney, Düsseldorf, 2007, http://www.mycomplexity.com/publications.asp

8. Etheredge, K., O'Keefe, J.: Getting A Handle On Complexity. Supply Chain Management Review, A.T. Kearney, 2010, http://www.atkearney.com/documents

9. Heywood, S., Spungin, J., Turnbull, D.: Cracking the complexity code. The McKinsey Quarterly, no.2, pp. 85 -95, June 2007

10. Birkinshaw, J., Heywood, S.: Putting organizational complexity. The McKinsey Quarterly, no. 3,2010

11. McKinsey and Company: McKinsey on Semiconductors, no.1, Autumn 2012

12. Aelker, J., Bauernhansl, T., Ehm, H.: Managing complexity in supply chains: a discussion of current approaches on the example of the semiconductor industry. Procedia CIRP 7 (2013) 79-84

13. Todnem By, R.: Organisational change management: A critical review. Journal of Change Management 5.4 (2005) 369-380

14. Kettinger, W. J., Teng, J. T., Guha, S.: Business process change: a study of methodologies, techniques, and tools. MIS quarterly (1997) 55-80

15. Weber, B., Reichert, M., Rinderle-Ma, S.: Change patterns and change support featuresenhancing flexibility in process-aware information systems. Data \& knowledge engineering 66.3 (2008) 438-466 
16. ElMaraghy, H. A., O. Kuzgunkaya, and R. J. Urbanic.: Manufacturing systems configuration complexity. CIRP Annals-Manufacturing Technology 54.1 (2005) 445-450

17. Deger, R.: Managing Complexity in Automotive Engineering. DSM 2007: Proceedings of the 9th International DSM Conference, Munich, Germany, 16.-18.10. 2007

18. Lindemann, U., and M. Maurer.: Facing multi-domain complexity in product development. The future of product development. Springer Berlin Heidelberg (2007) 351-361

19. Shannon, Claude E.: A Mathematical Theory of Communication. Bell System Technical Journal 21 (1948) 623-656

20. Schuh, G., Monostori, L., Csáji, B. C., Doering, S.: Complexity-based modeling of reconfigurable collaborations in production industry. CIRP Annals-Manufacturing Technology, 57.1 (2008) 445-450

21. Bohner, Shawn A., Arnold, Robert S.: Software change impact analysis. IEEE Computer Society Press, Los Alamitos CA, 1996

22. Haberfellner, R.: Systems Engineering: Methodik und Praxis. Ed. Walter F. Daenzer. Verlag Industrielle Organisation, 2002

23. Alard, R.: ETH Chair of Technology and Innovation Management, 2013. Systems Engineering Methodology (2013) http://www.timgroup.ethz.ch/education/Courses_at_TIMGROUP/spring_2013/SE_FS_201 3 final.pdf

24. Mylopoulos, J., Borgida, A., Jarke, M., Koubarakis, M.: Telos: Representing knowledge about information systems. ACM Transactions on Information Systems (TOIS) 8.4, (1990) 325-362

25. Dori, D.: Object Process Methodology: A Holistic Systems Paradigm; with CD-ROM. Springer, 2002

26. Dori, D.: Object-process analysis: maintaining the balance between system structure and behaviour." Journal of Logic and Computation 5.2 (1995) 227-249

27. Sharon, A., Dori, D.: A model-based approach for planning work breakdown structures of complex systems projects. Proc. 14th IFAC Symposium on Information Control Problems in Manufacturing, 2009

28. Berry, B. J., Kiel, L. D., \& Elliott, E.: Adaptive agents, intelligence, and emergent human organization: Capturing complexity through agent-based modeling. Proceedings of the National Academy of Sciences of the United States of America 99.Suppl 3 (2002) 7187-7188

29. Holling, Crawford S.: Understanding the complexity of economic, ecological, and social systems." Ecosystems 4.5 (2001) 390-405

30. Helbing, D., Balietti, S.: How to do agent-based simulations in the future: From modeling social mechanisms to emergent phenomena and interactive systems design. Tech. Rep. 1106-024, Santa Fe Institute, NM, USA (June 2011), santa Fe Working Paper, 2011

31. Eric, S. K., Giorgini, P., Maiden, N. (Eds.): Social modeling for requirements engineering. Mit Press, 2011

32. Salado, A., Nilchiani, R.: The Concept of Problem Complexity. Procedia Computer Science 28 (2014): 539-546

33. Sun, C., Rose, T., Ehm, H., Heilmayer, S.: Complexity Measurement in the Semiconductor Supply Chain. Presented at International Conference on Operations Research 2014: business analytics and optimization, Aachen, 2014

34. Bakker, Cornelis B.: Why people don't change. Psychotherapy: Theory, Research \& Practice 12.2 (1975) 164

35. Kotter, J. P., Cohen, D. S.: The heart of change: Real-life stories of how people change their organizations. Harvard Business Press, 2002 